\title{
DYNAMIC YOUNG MODULUS VARIATION THROUGH A TURBIDITIC SEDIMENTARY INTERVAL
}

\author{
Lidiane de Souza Garcia, Jorge Leonardo Martins and José Sampaio de Oliveira
}

\begin{abstract}
In reservoir development, the integration of results from distinct disciplines aims at increasing oil and gas production. In this context, geoscientists and engineers rely mainly on the records from geophysical well logging for controlling the spatial and depth variation of petrophysical properties of the formations. In this paper, we use geophysical well logging data through the turbiditic Namorado reservoir in Campos basin for calculating the spatial and depth variation of the isotropic Young modulus. The reservoir formation is mainly formed by subhorizontal thin layers of sandstones and shales. Such structural feature of the reservoir corroborated for approximating the sedimentary interval to a vertically transverse isotropic (VTI) medium using the Backus-averaging technique. We then calculated the correspondent Young moduli, in order to construct depth maps showing the spatial variation of VTI Young moduli in the reservoir formation. In the construction of the maps along depths selected a priori, an interpolation process was applied, which incorporates an inverse-distance square-weighted interpolator into a "search radius scheme". We evaluated the uncertainties in the interpolated maps by calculating statistical measures, revealing the robustness of the inverse-distance square-weighted interpolator coupled to the proposed "search radius scheme". For a selected depth, the resulting maps for the isotropic Young modulus show higher magnitudes if compared to the magnitudes of the VTI Young moduli (i.e., perpendicular and parallel) maps. This result confirms previous works which point out the importance of incorporating anisotropy in geomechanical studies, particularly in the analysis of in situ stresses in which use of elastic moduli is crucial. On the other hand, comparing the VTI Young moduli depth maps reveals that, in the Namorado reservoir, anisotropy induced by thin layers has weak influence on the calculation of Young modulus.
\end{abstract}

Keywords: geophysical well logs, effective VTI elastic stiffnesses, Backus averaging, dynamic Young modulus, spatial interpolation, Namorado reservoir.

RESUMO. No desenvolvimento de reservatórios, a integração de resultados de diversas disciplinas visa ao aumento da produção de óleo e gás. Nesse contexto, geocientistas e engenheiros contam principalmente com os registros de perfilagem geofísica de poços para controlar as variações espacial e em profundidade das propriedades petrofísicas das formações. Nesse artigo, usamos dados de perfilagem geofísica através do reservatório turbidítico de Namorado na bacia de Campos para calcular as variações espacial e em profundidade do módulo de Young isotrópico. A formação onde o reservatório se insere é composta principalmente por camadas sub-horizontais delgadas de arenitos e folhelhos. Tal feição estrutural do reservatório corroborou para aproximar o intervalo sedimentar a um meio transversalmente isotrópico vertical (TIV) usando a técnica de Backus. Calculamos então os módulos de Young correspondentes, a fim de construir mapas representativos da variação espacial dos módulos de Young TIV através da formação do reservatório. Na construção dos mapas ao longo das profundidades selecionadas a priori, aplicamos um processo de interpolação que incorpora um interpolador de distância inversa com pesos quadráticos num "esquema de raio de procura". Avaliamos as incertezas nos mapas interpolados através do cálculo de medidas estatísticas, revelando a robustez do interpolador de distância inversa com pesos quadráticos acoplado ao "esquema de raio de procura" proposto. Para uma profundidade selecionada, os mapas resultantes para o módulo de Young isotrópico mostram magnitudes maiores se comparadas às magnitudes dos mapas para o módulo de Young TIV (i.e., perpendicular e paralelo). Esse resultado confirma trabalhos anteriores que salientam a importância de incorporar a anisotropia em estudos geomecânicos, particularmente em análise de tensões in situ onde o uso de módulos elásticos é crucial. Por outro lado, a comparação dos mapas em profundidade para os módulos de Young TIV revela que, no reservatório Namorado, a anisotropia induzida por camadas delgadas tem fraca influência no cálculo do módulo de Young.

Palavras-chave: perfis geofísicos de poços, rigidezas elásticas efetivas para meio TIV, média de Backus, módulo de Young dinâmico, interpolação espacial, reservatório Namorado.

Coordenação da Área de Geofísica, Observatório Nacional, Ministério da Ciência e Tecnologia, Rua Gal. José Cristino, 77, São Cristóvão, 20921-400 Rio de Janeiro, RJ, Brazil. Phone: +55(21) 3504-9233; Fax: +55(21) 2580-7081 - E-mails: lidiane@on.br; jImartins@on.br; sampaio@on.br 


\section{INTRODUCTION}

The integration of distinct disciplines in the development of petroleum reservoirs aims primarily at maximizing production, consequently reducing drilling risk and costs (Pennington, 2001). In this way, to build up a thorough understanding of the reservoir body and the overburden formations, the geoscientists and engineers taking part in the reservoir development team must share detailed information on their investigations. Reservoir and drilling engineers in particular can benefit from integrating geoscientific techniques towards constructing a comprehensive geomechanical model for the reservoir under study (Zoback, 2007).

Laboratory core measurements and geophysical well logging are the main source of petrophysical information used in reservoir development. Laboratory measurements are limited to a small number of cores mostly from the reservoir formation, while well logging measurements provide information also from the overburden formations. Besides continuously sampling the lithologies at the vicinity of the borehole, measurements from well logging are exhaustively used for providing additional basic petrophysical properties (Dewan, 1983). For instance, the spontaneous potential and the gamma-ray logs allow evaluation of shaliness, which can be considered as a rock quality measure in terms of oil and gas production (Nery, 1990). Further, the calculation of recoverable oil volume requires estimation of porosity and connate water saturation. To estimate porosity, bulk density logs are more appropriate, while connate water saturation is estimated from electrical resistivity logs (Dewan, 1983; Nery, 1990). However, besides the estimation of basic physical properties, well log measurements can be further used in evaluating special physical properties as, for instance, the elastic moduli of the formations at the vicinity of the borehole (Elis \& Singer, 2007). The elastic moduli, specifically the Young modulus, are routinely used by reservoir and drilling engineers in the development of an oil and gas field. For instance, well drilling projects, drill bit selection and relevant drilling parameters demand a priori estimation of Young modulus and compressibility (Erling et al., 1991; Zoback, 2007). In this way, the implementation of a wellbore stability analysis, which is crucial for investigating in situ stresses at the vicinity of boreholes, relies on the a priori knowledge of the formation elastic moduli (Soares, 1992; Bell, 2003; Lasso-Lucero, 2010). A further example of the importance of elastic moduli in reservoir engineering is the study provided by Longuemare et al. (2002), which reviews coupling methods in the simulation of reservoir production. As pointed out in Longuemare et al. (2002) paper, several input parameters extracted from well log measurements, including the formation elastic moduli, are needed for implementing the simulation of reservoir production.
Well log measurements are the main source of information for estimating the elastic moduli of formations around boreholes. In this paper, we used bulk density and P- and S-wave sonic well log measurements from 36 wells of the data set prepared by Oliveira \& Martins (2011). The data set holds petrophysical information from 2940 to $3300 \mathrm{~m}$ depth of the upper Macaé formation containing the Namorado reservoir in Campos basin. The Namorado reservoir is mostly formed by subhorizontal thin sand-shale layers of turbiditic origin, with oil production in sandstone intervals (Tigre \& Lucchesi, 1986). Using the mentioned well log data set, we selected specific depths to map the spatial variation of Young modulus through the reservoir. Firstly, we prepared a data set containing isotropic Young modulus. Secondly, as subhorizontal thin layers characterize the inner structure of the reservoir, we approximated the formation to a transversely isotropic (TI) medium with vertical axis of symmetry (i.e., the so-called vertically transverse isotropic or VTI symmetry) in order to build up a further data set containing VTI Young modulus logs. Application of Backus averaging technique (Backus, 1962) allowed estimating the effective VTI stiffnesses for calculation of corresponding Young modulus logs. To generate isotropic and VTI Young modulus depth maps, we took into account an inversedistance square-weighted interpolator coupled with a "search radius scheme" (Weber \& Englund, 1992; Weber \& Englund, 1994). Calculation of statistical measures allowed analysis of uncertainties, showing interpolated Young modulus depth maps with stable magnitudes. Taking into account the relevance of anisotropy in the analysis of in situ stresses in sedimentary formations (Amadei, 1996; Lasso-Lucero, 2010), the resulting VTI Young modulus depth maps can be used for future implementation of geomechanical studies in the Namorado reservoir.

\section{METHODOLOGY}

In this section, we present the basic well log data set used for calculation of isotropic and anisotropic Young modulus logs. As the well log measurements are from a turbidite-type reservoir formed by subhorizontal thin layers, we approximated the sedimentary formation to a VTI medium. We present the formulas for Young modulus in homogeneous elastic media with isotropic and VTI symmetry, as well as the technique for estimating the effective VTI stiffnesses from bulk density and P- and S-wave sonic well logs. The end of the section describes the interpolator and the scheme of interpolation for construction of Young modulus depth maps through the Namorado reservoir. We summarize the methodology as follows: 
(1) preparation of the well log data set for application of the Backus-averaging technique;

(2) calculation of isotropic and VTI Young moduli; and

(3) construction of depth maps for isotropic and VTI Young moduli.

\section{The well log data set}

Using bulk density and sonic logs from vertical wells through the Namorado oil field, offshore Campos basin, Brazil, we prepared a data set containing the correspondent logs of isotropic and VTI Young moduli. The Namorado field is located $80 \mathrm{~km}$ offshore the Brazilian coast, covering an area of nearly $24 \mathrm{~km}^{2}$ and water layer thickness varying from 140 to $250 \mathrm{~m}$. Turbidity currents generated reservoir facies corresponding to poorly consolidated sandstones in the sedimentary interval from 2940 to $3300 \mathrm{~m}$ depth of the upper Macaé formation. Thin layers of organic and radioactive shales, siltstones and calcilutites alternate between sandstone reservoirs. In addition, the inner structure of the reservoir is mostly formed by subhorizontal thin layers (Tigre \& Lucchesi, 1986).

The region selected for studying the variation of Young moduli is represented in Figure 1, where the structural map of the Namorado oil field shows the main production and development wells drilled in the area. In this paper, we only used geophysical logs from the 36 wells located in the main portion of the reservoir. Taking the log measurements of bulk density and sonic velocity logs associated to the selected wells, we constructed logs of isotropic and VTI Young moduli. As a turbiditic reservoir can be approximated as a stack of alternating thin layers (Stovas et al., 2006), we applied the Backus-averaging technique to calculate the equivalent VTI stiffnesses (see section in the following) for subsequent computation of VTI Young modulus logs.

The whole set of selected wells holds measurements of physical properties at each $0.15 \mathrm{~m}$ depth. To complete the well log data set in this old exploration area, Augusto (2009) and Augusto \& Martins (2009) used least-squares regression analysis for empirically estimating the missing P-wave sonic logs in a large number of wells. Oliveira \& Martins (2011) then applied the methodology proposed in Lee (2006) for evaluating S-wave velocity logs from the resulting empirically-estimated P-wave velocity logs. In Figure 2, an interval of the lithology column of reference wells NA-01 (Fig. 2a) and RJS-0019 (Fig. 2b) allows correlating lithotypes with the anomalies in the log measurements. Due to the arcosean nature of the upper Macaé formation (Tigre \& Lucchesi, 1986), the gamma-ray logs of both wells in the first display from the left show high anomalies; in the second display, the anomalies in the deep electrical resistivity logs correlate with the oil-producing sandstone intervals of the lithology columns of both wells. In Figure 2a, the lithology column of well NA-01 exhibits several thin layers of calcilutites embedded in oil-producing sandstone intervals. In Figure $2 b$ we notice that thick layers of calcareous shales separate the oil-producing sandstone intervals in well RJS-0019. The plots at the right side of the lithology column show correspondent variation of bulk density, S- and P-wave velocity and logs of isotropic and VTI Young moduli at the vicinity of the reference wells. In both lithology columns, four lines indicate the depths selected for constructing the maps of isotropic and VTI Young moduli. The lines crossing the lithology column of reference well NA-01 intersect depths in sandstone intervals. For the reference well RJS-0019, the first three lines in the lithology column assign depths in calcareous shales, while the last line crosses a depth in a sandstone interval. In the next section, we review the formulation which leads to the derivation of formulas for calculating isotropic and VTI Young moduli in homogeneous elastic materials.

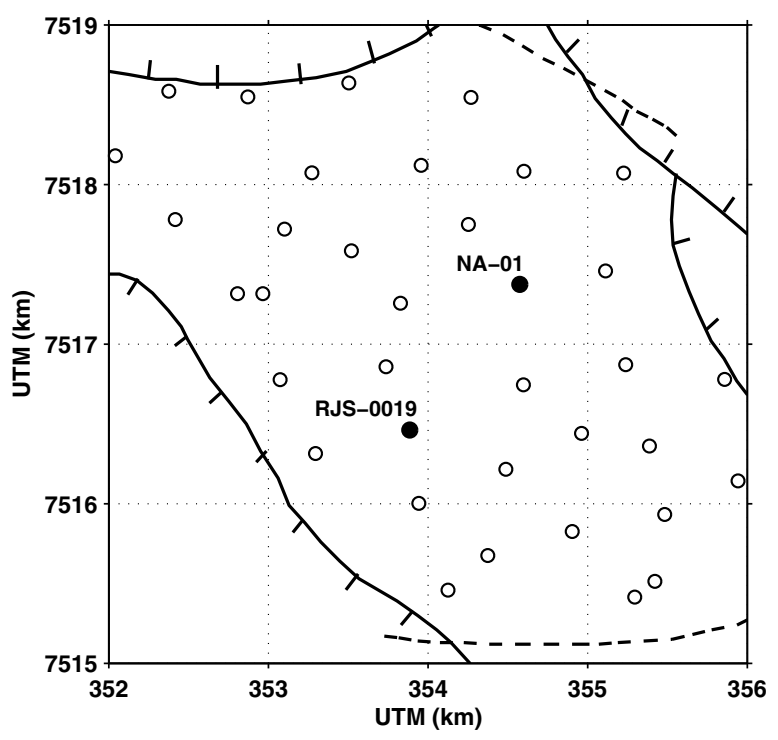

Figure 1 - Central region of the structural map of Namorado reservoir in Campos basin. Normal faults are the main structures bounding the reservoir; dashed lines represent non-inferred contacts. Well locations are marked with circles; the two reference wells NA-01 and RJS-0019 are assigned with filled circles.

\section{Formulas for the Young modulus}

The formulas for the Young modulus in homogeneous isotropic and VTI elastic media can be easily derived by algebraic manipulation of the normal stress equations, which are the product of 

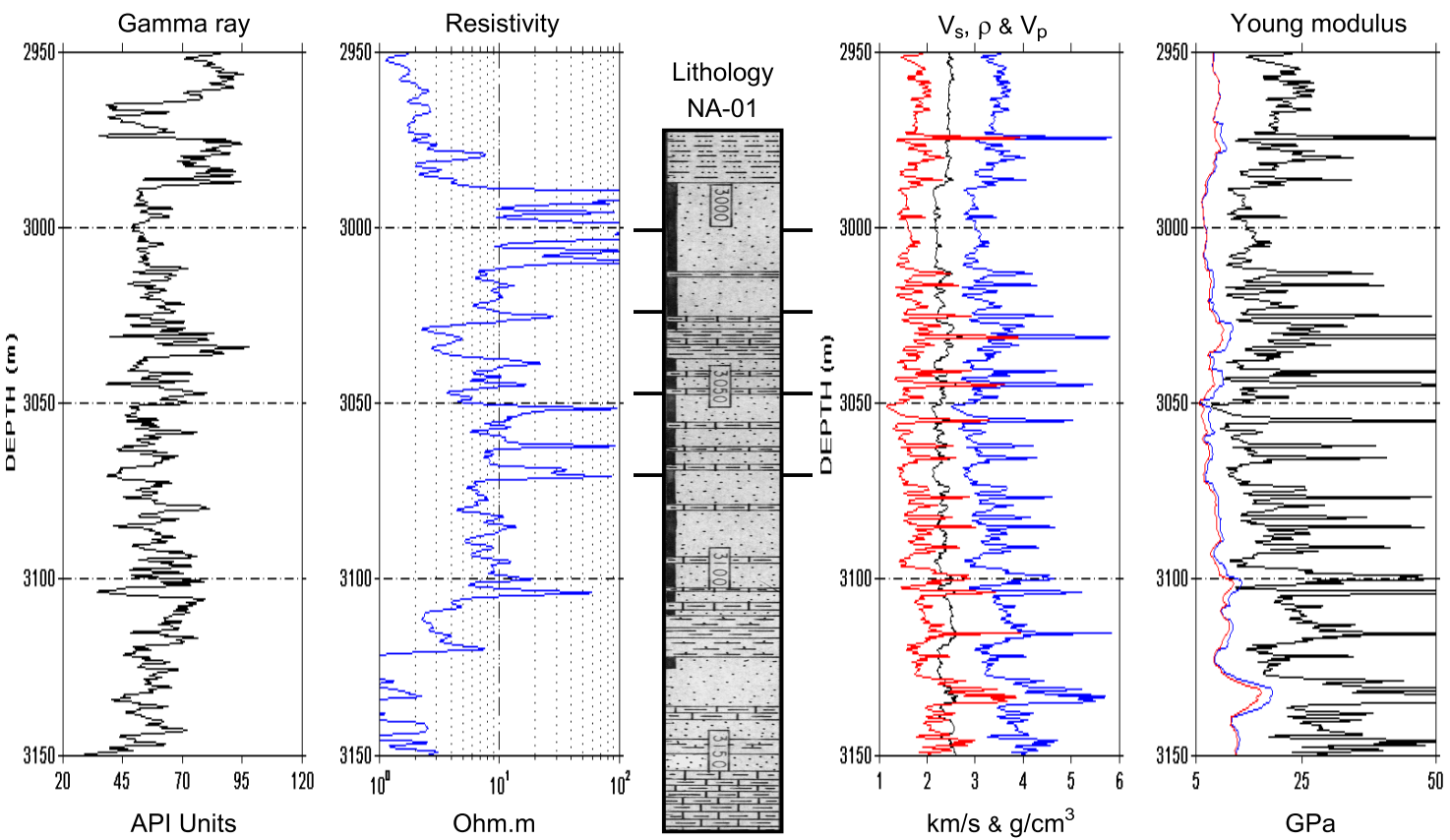

(a)
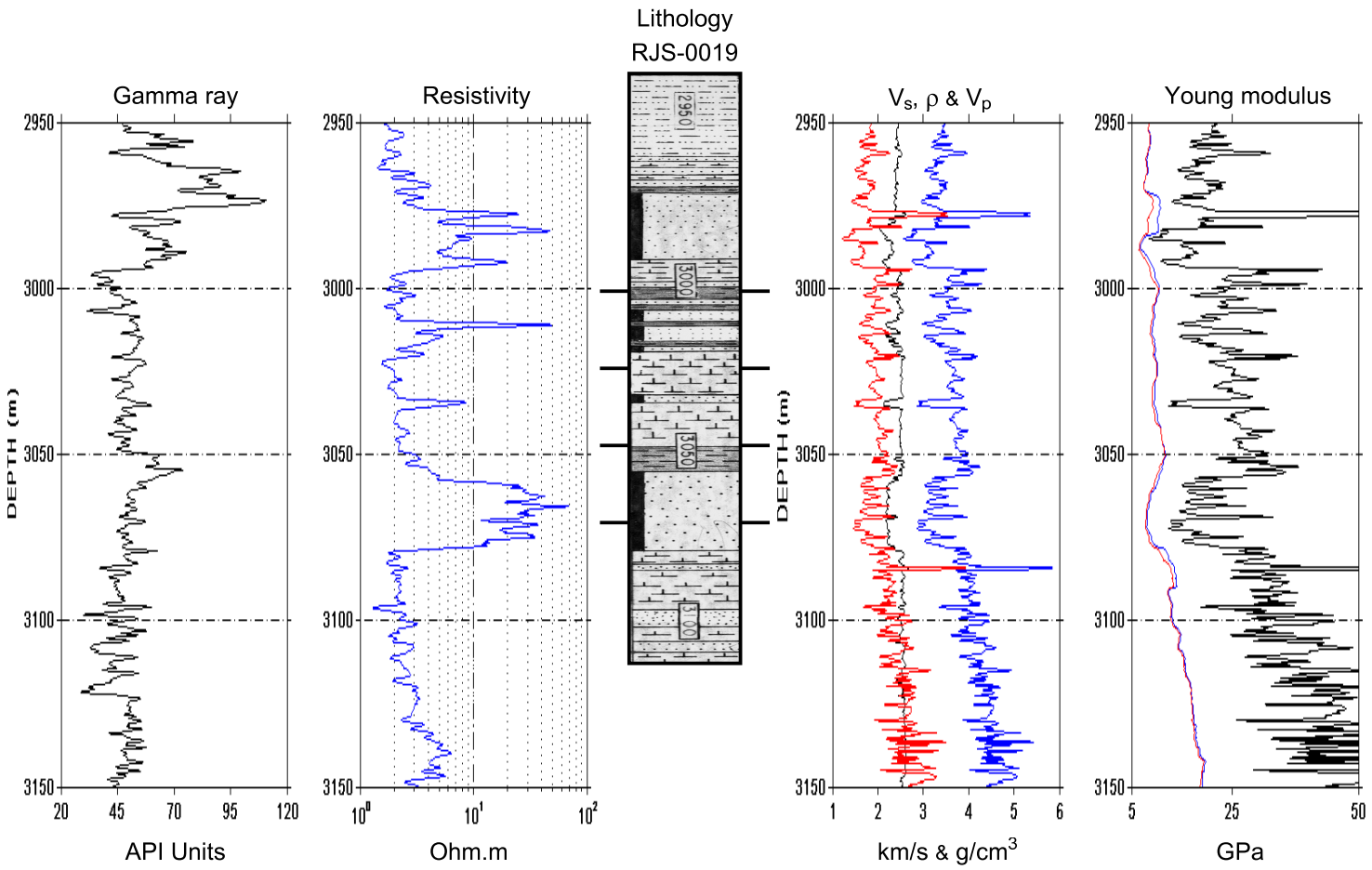

(b)

Figure 2 - Isotropic and VTI Young moduli in the upper Macaé formation at the vicinity of two reference wells: (a) Well NA-01 and (b) Well RJS-0019 (see well locations in Fig. 1). The middle plot shows the lithologic column, in which the crossing lines mark the depths selected for construction of maps of isotropic and VTI Young moduli: 3000, 3025, 3050 and 3075 m. The gamma-ray (API units) and the deep electrical resistivity (Ohm.m) logs are in the left plots, respectively. The plot after the lithology column displays the bulk density (black curve, $\mathrm{g} / \mathrm{cm}^{3}$ ) and the velocity logs (S-wave in red and P-wave in blue, $\mathrm{km} / \mathrm{s}$ ). The rightmost plot exhibits the depth variation of Young modulus in GPa. The black curve shows the isotropic Young modulus E, while red and blue curves display the parallel and perpendicular VTI Young moduli, $\mathrm{E}_{\|}$and $\mathrm{E}_{\perp}$, respectively. Note that the magnitude of $\mathrm{E}$ is higher than $\mathrm{E}_{\perp}$ and $\mathrm{E}_{\|}$. Moreover, $\mathrm{E}_{\perp}>\mathrm{E}_{\|}$is consistent with $\mathrm{Eq}$. (8). 
expanding the generalized Hooke's law widely known from the linear elasticity theory (Love, 1944). Assuming a body submitted to an external applied force, Hooke's law states that the observed strains are proportional to the magnitude of the applied force. In tensor notation, the generalization of Hooke's law can be written as (Aki \& Richards, 1980; Helbig, 1994)

$$
\tau_{\mathrm{ij}}=\mathrm{C}_{\mathrm{ijpq}} \epsilon_{\mathrm{pq}},
$$

in which the indexes $i, j, p$ and $q$ vary from 1 to 3 . The quantities $\tau_{\mathrm{ij}}$ and $\epsilon_{\mathrm{pq}}$ are second-order tensors representing the acting stresses and the corresponding strains, respectively.

In Eq. (1), Hooke's law states that the resulting strains are linearly related to applied stresses by means of elastic parameters of the medium represented by the fourth-order stiffness tensor $\mathrm{C}_{\mathrm{ijpq}}$. Due to the symmetry of the stress and strain tensor, that is, $\tau_{\mathrm{ij}}=\tau_{\mathrm{ji}}$ and $\epsilon_{\mathrm{pq}}=\epsilon_{\mathrm{qp}}$, the stiffness tensor $\mathrm{C}_{\mathrm{ijpq}}$ is also symmetric (i.e., $\mathrm{C}_{\mathrm{ijpq}}=\mathrm{C}_{\mathrm{ijqp}}=\mathrm{C}_{\mathrm{jipq}}=\mathrm{C}_{\mathrm{pqij}}$ ). For a general anisotropic elastic material, $\mathrm{C}_{\mathrm{ijpq}}$ contains 81 elements. In the literature, the elements of the stiffness tensor are sometimes referred to as elastic moduli (Love, 1944). However, in order to discriminate the elements of $\mathrm{C}_{\mathrm{ijpq}}$ against the Young modulus, we hereafter refer to the elements of the stiffness tensor as elastic stiffnesses. The Young modulus will be simply referred to as elastic modulus.

The symmetry property of $\tau_{\mathrm{ij}}$ and $\epsilon_{\mathrm{pq}}$ allows representing these tensors in matrix form. The physical meaning of the correspondent elements depends on the indexes of the tensor under analysis. The diagonal elements of the stress tensor (i.e., $\mathrm{i}=\mathrm{j}$ ) represent the normal stresses; for the strain tensor, the diagonal elements (i.e., $\mathrm{p}=\mathrm{q}$ ) are named longitudinal strains. On the other hand, off-diagonal elements of the stress tensor (i.e., $i \neq j$ ) represent shearing stresses, while off-diagonal elements of the strain tensor (i.e., $p \neq q$ ) are named shearing strains. Still, the symmetry property allows reducing the number of elements of the stiffness tensor $\mathrm{C}_{\mathrm{ijpq}}$ from 81 to 21 independent elements. In this way, an abbreviated notation - also known as Voigt notation - facilitates representing the elements of the stiffness tensor in matrix form. In this two-index notation, the pair of indexes ij is substituted by $\mathrm{m}$, and pq by $\mathrm{n}$. When $\mathrm{i}=\mathrm{j}$ or $\mathrm{p}=\mathrm{q}$, we use the following substitutions: $11 \Rightarrow 1,22 \Rightarrow 2$ and $33 \Rightarrow 3$. However, when $\mathrm{i} \neq \mathrm{j}$ or $\mathrm{p} \neq \mathrm{q}$, the substitutions are as follows: 23 or $32 \Rightarrow 4,13$ or $31 \Rightarrow 5$ and 12 or $21 \Rightarrow 6$. Use of the abbreviated notation yields a $6 \times 6$ symmetric matrix referred to as the elastic matrix (Aki \& Richards, 1980; Helbig, 1994). In terms of units, the elements of the stiffness tensor $\mathrm{C}_{\mathrm{ijpq}}$ are generally represented in $\mathrm{GPa}$.
Applying the abbreviated notation to Hooke's law in Eq. (1), we can obtain the system of algebraic equations only considering normal stresses $\tau_{1}, \tau_{2}$ and $\tau_{3}$, that is,

$$
\left[\begin{array}{l}
\tau_{1} \\
\tau_{2} \\
\tau_{3}
\end{array}\right]=\left[\begin{array}{lll}
\mathrm{A}_{11} & \mathrm{~A}_{12} & \mathrm{~A}_{13} \\
\mathrm{~A}_{21} & \mathrm{~A}_{22} & \mathrm{~A}_{23} \\
\mathrm{~A}_{31} & \mathrm{~A}_{32} & \mathrm{~A}_{33}
\end{array}\right]\left[\begin{array}{c}
\epsilon_{1} \\
\epsilon_{2} \\
\epsilon_{3}
\end{array}\right],
$$

which can be easily solved for obtaining the equation for the Young modulus. The quantities $\mathrm{A}_{\mathrm{mn}}$ in $\mathrm{Eq}$. (2) are the elements of the density-normalized elastic stiffness tensor

$$
\mathrm{a}_{\mathrm{ijpq}}=\frac{1}{\rho} \mathrm{C}_{\mathrm{ijpq}},
$$

after using the abbreviated notation as above (i.e., $\mathrm{a}_{\mathrm{ijpq}} \Rightarrow$ $\left.A_{m n}\right)$. Note that only part of the elastic matrix is represented in Eq. (2). Moreover, the square root of $A_{m n}$ has velocity unit (Wright, 1987); for density given in $\mathrm{g} / \mathrm{cm}^{3}$, the elements of $\mathrm{A}_{\mathrm{mn}}$ are represented in $(\mathrm{km} / \mathrm{s})^{2}$ (Helbig, 1994). In the following we present the formulas for the Young modulus, specifying the elastic matrix for homogeneous isotropic and VTI elastic media.

Homogeneous isotropic elastic medium - The elements of the elastic matrix for homogeneous isotropic media are: $\mathrm{A}_{11}=$ $\mathrm{A}_{22}=\mathrm{A}_{33}=(\lambda+2 \mu) / \rho, \mathrm{A}_{12}=\mathrm{A}_{13}=\mathrm{A}_{23}=$ $\mathrm{A}_{33}-2 \mathrm{~A}_{44}=\lambda / \rho$ and $\mathrm{A}_{44}=\mathrm{A}_{55}=\mathrm{A}_{66}=\mu / \rho$. The quantities $\lambda$ and $\mu$ are referred to as the Lamé elastic parameters (Love, 1944; Aki \& Richards, 1980). Then, assuming a configuration in which a homogeneous isotropic elastic bar is fixed at one end while a force of magnitude $\mathrm{F}$ acts along a selected coordinate axis (for instance, the $\mathrm{x}_{1}$ axis), the normal stresses in Eq. (2) reduces to $\tau_{1}=\mathrm{F}$ and $\tau_{2}=\tau_{3}=0$. Under these assumptions, solving the correspondent algebraic system yields the relation for the isotropic Young modulus,

$$
\mathrm{E}=\frac{\mu(3 \lambda+2 \mu)}{\lambda+\mu}=\frac{\mathrm{A}_{44}\left(3 \mathrm{~A}_{33}-4 \mathrm{~A}_{44}\right)}{\mathrm{A}_{33}-\mathrm{A}_{44}} .
$$

As $\lambda$ and $\mu$ are represented in $\mathrm{GPa}$, the unit for the isotropic Young modulus $\mathrm{E}$ is also $\mathrm{GPa}$.

Homogeneous VTI elastic medium - The elements of the elastic matrix for homogeneous VTI media, with $\mathrm{x}_{3}$ corresponding to the vertical axis of symmetry oriented downwards, are: $\mathrm{A}_{11}=\mathrm{A}_{22}=\left(\lambda_{\perp}+2 \mu_{\perp}\right) / \rho, \mathrm{A}_{33}=\left(\lambda_{\|}+2 \mu_{\|}\right) / \rho$, $\mathrm{A}_{12}=\mathrm{A}_{11}-2 \mathrm{~A}_{66}=\lambda_{\perp} / \rho, \mathrm{A}_{13}=\mathrm{A}_{23}=\nu / \rho$, $\mathrm{A}_{44}=\mathrm{A}_{55}=\mu_{\|} / \rho$ and $\mathrm{A}_{66}=\mu_{\perp} / \rho$. The quantities $\lambda_{\perp}, \lambda_{\|}, \mu_{\perp}, \mu_{\|}$and $\nu$ are referred to as the modified Lamé elastic parameters for homogeneous VTI media (Helbig, 1994), with units in GPa. For density in $\mathrm{g} / \mathrm{cm}^{3}$, the elements of the density-normalized stiffness matrix $A_{i j}$ is given in $(\mathrm{km} / \mathrm{s})^{2}$. The 
subscripts $\perp$ and $\|$ indicate that the corresponding quantity is defined with respect to a direction perpendicular or parallel to the axis of symmetry, respectively. As a result, the elastic moduli in homogeneous VTI media are defined with respect to the symmetry axis. For the derivation of the Young modulus formula using the algebraic system represented in Eq. (2), we consider two configurations involving a homogeneous VTI elastic bar fixed at one end: (1) a force of magnitude $\mathrm{F}_{\perp}$ acts along a coordinate axis perpendicular to the vertical axis of symmetry $\mathrm{x}_{3}$; and (2) a force of magnitude $\mathrm{F}_{\|}$acts along a coordinate axis parallel to the vertical axis of symmetry $\mathrm{x}_{3}$. For the first configuration, we take $\tau_{2}=\mathrm{F}_{\perp}$ and $\tau_{1}=\tau_{3}=0$. Hence, the algebraic system in Eq. (2) yields the formula for the Young modulus perpendicular to the axis of symmetry $\mathrm{E}_{\perp}$, as follows

$$
\mathrm{E}_{\perp}=\frac{\left(\mathrm{A}_{11}-\mathrm{A}_{12}\right)\left[\mathrm{A}_{33}\left(\mathrm{~A}_{11}+\mathrm{A}_{12}\right)-2 \mathrm{~A}_{13}^{2}\right]}{\mathrm{A}_{11} \mathrm{~A}_{33}-\mathrm{A}_{13}^{2}} .
$$

Note that, due to the VTI symmetry, Eq. (5) can also be obtained by selecting $\tau_{1}=\mathrm{F}_{\perp}$ and $\tau_{2}=\tau_{3}=0$.

For the second configuration involving a homogeneous VTI elastic bar as above, we take $\tau_{3}=\mathrm{F}_{\|}$and $\tau_{1}=\tau_{2}=0$. Solving Eq. (2) yields the formula for the Young modulus parallel to the axis of symmetry $\mathrm{E}_{\|}$, written as

$$
\mathrm{E}_{\|}=\mathrm{A}_{33}-\frac{2 \mathrm{~A}_{13}^{2}}{\mathrm{~A}_{11}+\mathrm{A}_{12}} .
$$

An interesting relation between $\mathrm{E}_{\perp}$ and $\mathrm{E}_{\|}$can be obtained after multiplying the numerator and the denominator of $\mathrm{Eq}$. (5) by $\left(\mathrm{A}_{11}+\mathrm{A}_{12}\right)^{-1}$. Further algebraic manipulation results in

$$
\frac{E_{\perp}}{E_{\|}}=\frac{A_{11}^{2}-A_{12}^{2}}{A_{11} A_{33}-A_{13}^{2}} .
$$

In VTI elastic media, the density-normalized stiffnesses $A_{i j}$ are all positive, while the following relations hold: $A_{11}>A_{33}$, $\mathrm{A}_{11}>\mathrm{A}_{66}$ and $\mathrm{A}_{12}=\mathrm{A}_{11}-2 \mathrm{~A}_{66}>\mathrm{A}_{13}$ (Helbig, 1994). Using these relations, Eq. (7) gives $\left(A_{11}^{2}-A_{12}^{2}\right)>$ $\left(\mathrm{A}_{11} \mathrm{~A}_{33}-\mathrm{A}_{13}^{2}\right)$, yielding

$$
\frac{\mathrm{E}_{\perp}}{\mathrm{E}_{\|}}>1 .
$$

As a remark, in homogeneous weakly VTI elastic media, $\mathrm{E}_{\perp} / \mathrm{E}_{\|} \approx 1$. Furthermore, as long as in homogeneous isotropic elastic media $\mathrm{A}_{11}=\mathrm{A}_{33}$ and $\mathrm{A}_{12}=\mathrm{A}_{13}$, Eq. (7) reduces to unity.

In order to apply the formulas for the Young modulus in Eqs. (5) and (6), we used a data set containing logs of equivalent density-normalized VTI elastic stiffnesses. Based on weighted averaging formulas for calculating the five equivalent VTI stiffnesses, i.e., the so-called Backus-averaging technique (Backus, 1962), Oliveira \& Martins (2010) constructed this data set using the same geophysical well logs of the Namorado reservoir described above. Basically, the Backus-averaging technique corresponds to a filtering operation within a specified frequencydependent window length (Liner \& Fei, 2006; Bayuk et al., 2008; Tiwary et al., 2009). For estimating the elastic stiffnesses of the equivalent VTI medium (i.e., $c_{11}^{\mathrm{vti}}, c_{13}^{\mathrm{vti}}, c_{33}^{\mathrm{vti}}, c_{55}^{\mathrm{vti}}$ and $c_{66}^{\mathrm{vti}}$ ), the weighted average formulas are (Backus, 1962)

$$
\begin{gathered}
\frac{1}{c_{33}^{\mathrm{vti}}}=\left\langle\frac{1}{c_{33}^{(\mathrm{i})}}\right\rangle, \quad \frac{1}{c_{55}^{\mathrm{vti}}}=\left\langle\frac{1}{c_{55}^{(\mathrm{i})}}\right\rangle, \quad c_{66}^{\mathrm{vti}}=\left\langle c_{66}^{(\mathrm{i})}\right\rangle, \\
\frac{c_{13}^{\mathrm{vti}}}{c_{33}^{\mathrm{vti}}}=\left\langle\frac{c_{13}^{(\mathrm{i})}}{c_{33}^{(\mathrm{i})}}\right\rangle \text { and } \\
c_{11}^{\mathrm{vti}}-\frac{\left[c_{13}^{\mathrm{vti}}\right]^{2}}{c_{33}^{\mathrm{vti}}}=\left\langle c_{11}^{(\mathrm{i})}-\frac{\left[c_{13}^{(\mathrm{i})}\right]^{2}}{c_{33}^{(\mathrm{i})}}\right\rangle
\end{gathered}
$$

where, in order to complete the VTI elastic matrix, the stiffness $c_{12}^{\mathrm{vti}}$ is calculated as $c_{12}^{\mathrm{vti}}=c_{11}^{\mathrm{vti}}-2 c_{66}^{\mathrm{vti}}$. In the presence of low dominant wavelength, a stack of alternating sequence of small-thickness homogeneous elastic isotropic layers exhibits VTI anisotropy behavior (Postma, 1955; Backus, 1962; Levin, 1984). Then, the following isotropic elastic stiffnesses must be substituted in Eqs. (9): $c_{12}^{(\mathrm{i})}=c_{13}^{(\mathrm{i})}=c_{23}^{(\mathrm{i})}=\lambda^{(\mathrm{i})}, c_{11}^{(\mathrm{i})}=$ $c_{22}^{(\mathrm{i})}=c_{33}^{(\mathrm{i})}=\lambda^{(\mathrm{i})}+2 \mu^{(\mathrm{i})}$ and $c_{44}^{(\mathrm{i})}=c_{55}^{(\mathrm{i})}=c_{66}^{(\mathrm{i})}=\mu^{(\mathrm{i})}$. Taking into account well log data, the i-th log measurement of bulk density $\rho_{\mathrm{i}}, \mathrm{P}$-wave sonic velocity $\alpha_{\mathrm{i}}$ and S-wave sonic velocity $\beta_{\mathrm{i}}$, allows estimating the Lamé parameters as follows: $\lambda_{\mathrm{i}}=\rho_{\mathrm{i}}\left(\alpha_{\mathrm{i}}^{2}-2 \beta_{\mathrm{i}}^{2}\right)$ and $\mu_{\mathrm{i}}=\rho_{\mathrm{i}} \beta_{\mathrm{i}}^{2}$. Note the use of the abbreviated notation in Eqs. (9), where $c_{\mathrm{ij}}^{\mathrm{vti}}$ represents an element of the elastic stiffness tensor $\mathrm{C}_{\mathrm{ijpq}}$ for VTI anisotropy.

In the implementation of Backus filtering process, we used an averaging window length with 55 samples, corresponding to a dominant frequency of nearly $40 \mathrm{~Hz}$. Using the same window length, measurements of bulk density $\rho_{\mathrm{i}}$ provided the inputs for estimating the apparent density $\log \left\langle\rho^{(\mathrm{i})}\right\rangle$ by means of a weighted averaging formula. This allowed estimating the correspondent logs of density-normalized VTI elastic stiffnesses, $\mathrm{A}_{\mathrm{ij}}^{\mathrm{vti}}$, for subsequent application of Eqs. (5) and (6) in the calculation of VTI Young moduli. Next section presents the interpolation process for generation of Young modulus depth maps through the Namorado reservoir. 


\section{Computation of Young modulus maps}

We applied the same procedure as in Oliveira \& Martins (2011) to represent the spatial variation of isotropic and VTI Young moduli through the Namorado reservoir. The construction of the Young modulus maps relied on the input data set containing the $\mathrm{E}, \mathrm{E}_{\perp}$ and $\mathrm{E}_{\|}$logs computed with Eqs. (4), (5) and (6), respectively. As shown in the lithology columns of reference wells NA-01 and RJS-0019 in Figure 2, the depths specified for generating the Young modulus maps are 3000, 3025, 3050 and $3075 \mathrm{~m}$.

After the computation of the $\mathrm{E}, \mathrm{E}_{\perp}$ and $\mathrm{E}_{\|}$logs for each well of our data set described above, two basic steps are needed for generating the correspondent Young modulus map: gridding and interpolation. The gridding step uses cells with regular dimensions for discretizing the area under study defined in Figure 1. The intersection of a specified depth with well locations forms a set of control points (i.e., correspondent magnitudes for the Young modulus) serving as the input for the interpolation step. The interpolated Young modulus value resulting from the interpolation step is then associated to the center of an individual cell of the grid. To interpolate the Young modulus using the selected set of control points, we applied the inverse-distance interpolator studied in Weber \& Englund (1992) and Weber \& Englund (1994), written as follows

$$
Z_{j}^{r_{s}}=\sum_{i=1}^{n} Z_{i} \omega_{i}^{r_{s}} .
$$

The quantity $Z_{j}^{r_{s}}$ denotes the interpolated Young modulus value in the $j^{\text {th }}$ grid cell. The interpolator requires definition of a search radius $r_{s}$ in order to select a set of $n$ control points for evaluating the weights $\omega_{i}^{r_{s}}$. In this way, $Z_{i}$ is the Young modulus value in the $i^{\text {th }}$ control point inside the search radius $r_{s}$. To the $i^{\text {th }}$ control point, a corresponding weight $\omega_{\mathrm{i}}^{\mathrm{r}_{\mathrm{s}}}$ is associated. The formula for computing the weights $\omega_{i}^{r_{s}}$ is based on the distance $\mathrm{d}_{\mathrm{i}}$ between the center of a grid cell and the $\mathrm{i}^{\text {th }}$ control point inside the search radius,

$$
\omega_{i}^{r_{s}}=\frac{\left[\left(r_{s}-d_{i}\right) / d_{i}\right]^{m}}{\sum_{j=1}^{n}\left[\left(r_{s}-d_{j}\right) / d_{j}\right]^{m}} .
$$

As commented in Oliveira \& Martins (2011), two possible limiting situations can occur in Eq. (11): $r_{s}=d_{i}$ and $d_{i}=0$. In the first situation, $r_{\mathrm{s}}=\mathrm{d}_{\mathrm{i}}$ if a control point occurs exactly in the circumference defined by the search radius. We avoided this situation by taking only control points inside the circumference defined by $r_{s}$. The second situation $d_{i}=0$ refers to a control point situated exactly in the center of the correspondent grid cell. To circumvent this situation, we discarded control points very near the center of the grid cell (for instance, having $\left.\mathrm{d}_{\mathrm{i}}<10^{-3} \mathrm{~m}\right)$. Still concerning Eq. (11), it can be noticed a simultaneous influence of the search radius $r_{s}$ in computing the weights $\omega_{\mathrm{i}}^{\mathrm{r}_{\mathrm{s}}}$ and in the interpolation of the Young modulus. In general the gridded area is irregularly populated by control points, possibly leading to a situation where the calculation of the weight is critical (i.e., the situation when the selected search radius surrounds no control points). In order to avoid capturing no control points we used here the same procedure as in Oliveira \& Martins (2011), applying a variable search radius during the interpolation process. The section in the following shows Young modulus maps using a variable search radius from 2000 to $3000 \mathrm{~m}$. As we selected $\mathrm{m}=2$ in Eq. (11) for constructing the maps, the interpolator in Eq. (10) reduced to an inverse-distance square-weighted interpolator. Weber \& Englund (1992) and Weber \& Englund (1994) report that taking $\mathrm{m}=2$ in Eq. (10) provides an interpolation result equivalent to a kriging operation.

\section{RESULTS}

To represent the spatial variation of isotropic and VTI Young moduli over the Namorado reservoir, we took into account the four selected depths shown in the lithologic columns of the reference wells in Figure 2. For each selected depth, the Young modulus maps are organized in Figures 3 and 4 as follows: the isotropic $\mathrm{E}$ map is displayed at the top, while the maps for $\mathrm{E}_{\|}$and $\mathrm{E}_{\perp}$ are exhibited in the middle and at the bottom, respectively. To study the influence of VTI anisotropy on the Young modulus, we generated depth maps showing the deviations of $\mathrm{E}_{\|}$from $\mathrm{E}_{\perp}$ (i.e., $\mathrm{E}_{\perp}-\mathrm{E}_{\|}$) and the ratio $\mathrm{E}_{\perp} / \mathrm{E}_{\|}$at the top and bottom, respectively, of Figures 5 and 6 . The maps at 3000 and $3025 \mathrm{~m}$ depth are displayed in Figures 3 and 5 , while Figures 4 and 6 shows the maps at 3050 and $3075 \mathrm{~m}$ depth. As the four selected depths are separated by $25 \mathrm{~m}$, interpretation of maps of the same type gives insight on the depth variation of the Young modulus in the formation under study. In order to investigate uncertainties in the Young modulus maps $\mathrm{E}, \mathrm{E}_{\|}$and $\mathrm{E}_{\perp}$, we present in Table 1 the computation of statistical measures for three specific scenarios: (a) using only the control points entering the interpolation step, (b) using only the overall interpolated grid points, and (c) using only the interpolated grid points in the center of the map surrounded by a circular region with radius of $1.5 \mathrm{~km}$. For a specific Young modulus depth map, the analysis of the statistical measures in Table 1 clearly points out the robust- 

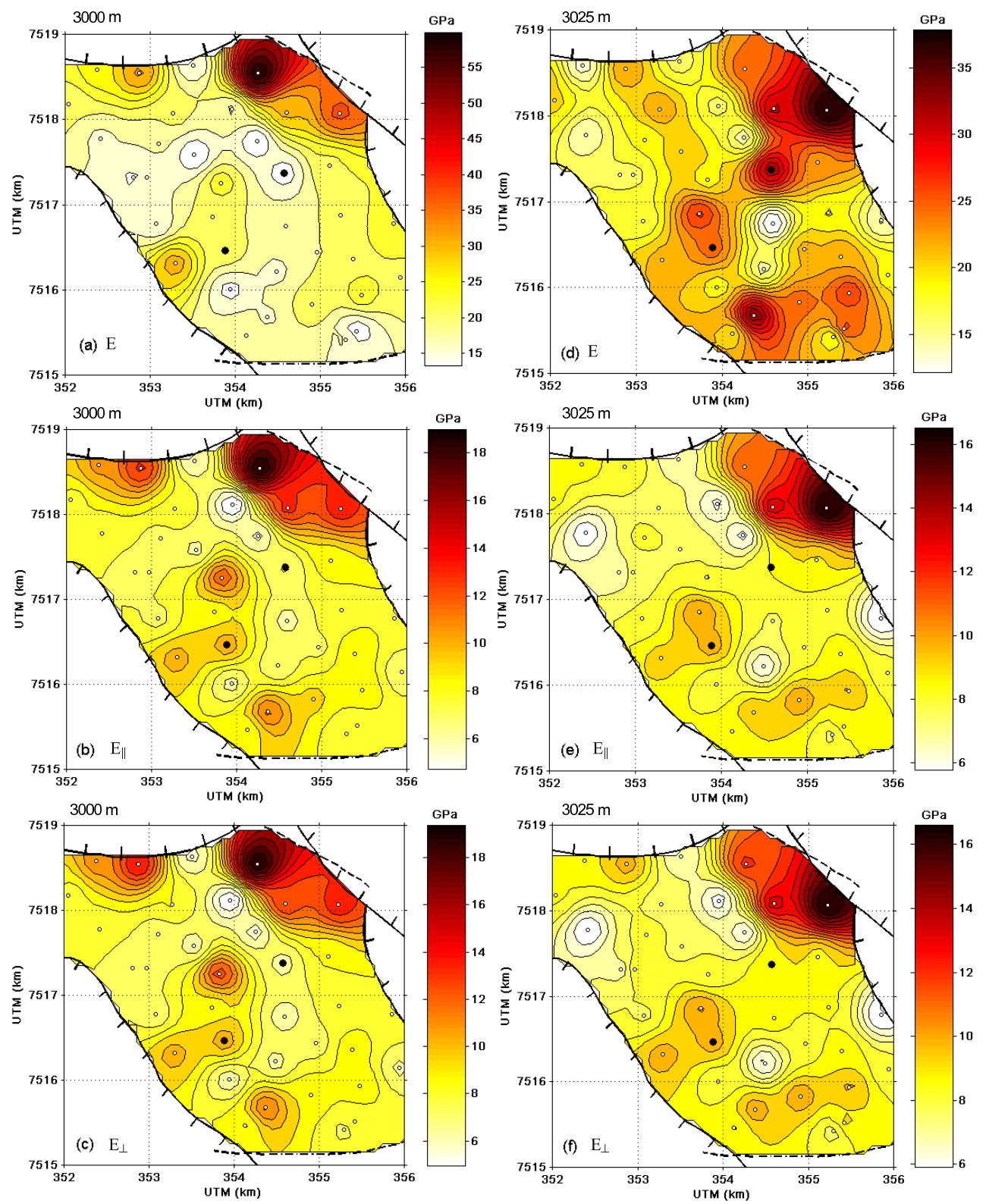

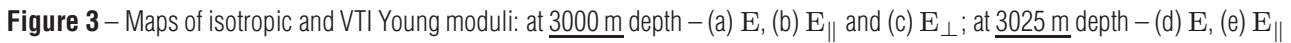
and (f) $\mathrm{E}_{\perp}$. Filled circles locate the reference wells NA-01 and RJS-0019 (see Figs. 1 and 2).

ness of the inverse-distance interpolator in Eq. (10) with weights calculated using Eq. (11).

Analysis of the maps in Figures 3 and 4 shows that isotropic Young modulus has magnitudes significantly higher than the VTI Young moduli. This property is clearly exhibited also in Figure 2, in the correspondent logs associated to the reference wells NA-01 and RJS-0019. Also remarkable is the observation of the magnitudes in the depth maps for $\mathrm{E}_{\perp}-\mathrm{E}_{\|}$and $\mathrm{E}_{\perp} / \mathrm{E}_{\|}$ (see Figs. 5 and 6), confirming the relationship in Eq. (8). The small magnitudes occurring in these maps reveal that the upper
Macaé formation presents mostly weak strength of VTI anisotropy. We present in the following a more detailed interpretation of the features appearing in the Young modulus depth maps. In the analysis, we focused on the facies intercepted by the four selected depths shown in the lithology columns of the reference wells in Figure 2.

Let us consider the features in the maps of isotropic Young modulus. Significant overall changes can be noticed as depth increases from 3000 to $3075 \mathrm{~m}$. This clearly reflects the distribution of heterogeneities in the upper Macaé formation, with com- 

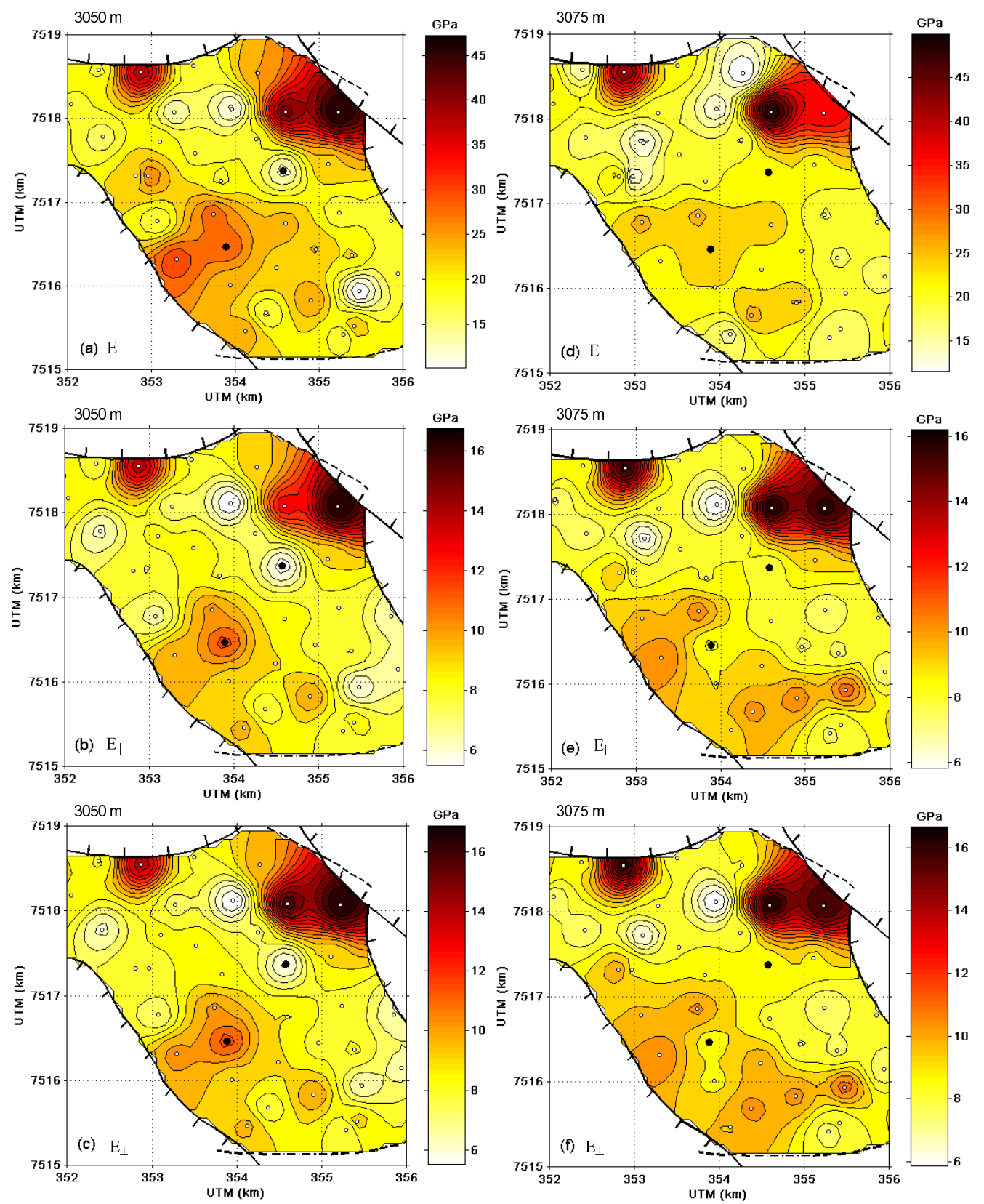

Figure 4 - Maps of isotropic and VTI Young moduli: at $\underline{3050 \mathrm{~m}}$ depth - (a) E, (b) $\mathrm{E}_{\|}$and (c) $\mathrm{E}_{\perp}$; at $\underline{3075 \mathrm{~m}}$ depth - (d) E, (e) $\mathrm{E}_{\|}$ and (f) $\mathrm{E}_{\perp}$. Filled circles locate the reference wells NA-01 and RJS-0019 (see Figs. 1 and 2).

plex distribution of heterogeneities at $3025 \mathrm{~m}$ (Fig. 3d) and at $3050 \mathrm{~m}$ (Fig. 4a). In Figure 3a, the map at $3000 \mathrm{~m}$ shows high values for the isotropic Young modulus in the northern part of the formation. These high magnitudes of the isotropic Young modulus change orientation somewhere between 3000 and $3025 \mathrm{~m}$ depth - mostly because of the inner structural geologic complexity of the formation, keeping along the northeastern direction from 3025 to $3075 \mathrm{~m}$ depth (see Figs. 3d, 4a, and 4d).
As shown in the maps for $\mathrm{E}_{\|}$(see Figs. 3b, 3e, 4b, and 4e) and the maps for $\mathrm{E}_{\perp}$ (see Figs. 3c, 3f, 4c, and 4f), similar analysis as in the preceding paragraph applies for the VTI Young moduli. The remarkable northwestern-southeastern trend observed in the VTI Young modulus depth maps may be revealing lithology continuity along this direction. For the depths of 3000 and $3025 \mathrm{~m}$, the maps of $\mathrm{VTI}$ Young moduli $\mathrm{E}_{\|}$and $\mathrm{E}_{\perp}$ present similar features with an overall distribution of small magnitudes. 

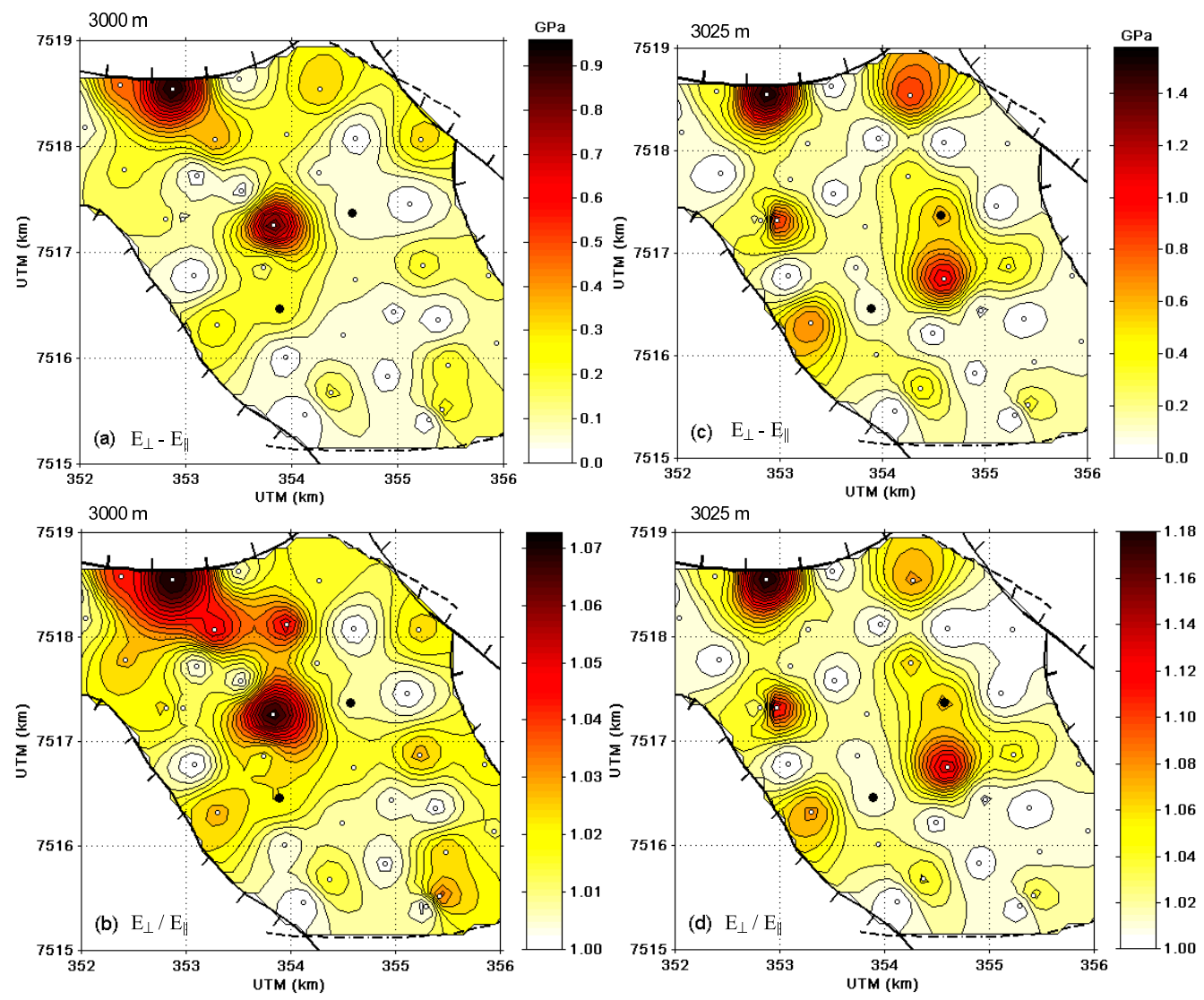

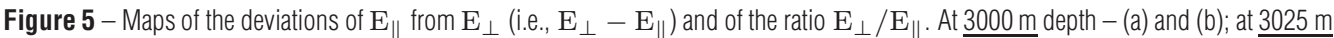
depth - (c) and (d). The maps of deviations $\mathrm{E}_{\perp}-\mathrm{E}_{\|}$are in (a) and (c). The ratio $\mathrm{E}_{\perp} / \mathrm{E}_{\|}$is plotted in (b) and (d). Filled circles locate the reference wells NA-01 and RJS-0019 (see Figs. 1 and 2).

As in the isotropic maps, the upper parts show high contrasts in the map for $\mathrm{E}_{\|}$(see Figs. 3b and 3e), and in the map for $\mathrm{E}_{\perp}$ (see Figs. 3c and 3f). In the northern part of these maps, the inner geologic complexity of the formation causes the heterogeneity to change direction from northern to northeastern direction. In the northwestern part of the $\mathrm{E}_{\|}$and $\mathrm{E}_{\perp}$ maps, a prominent feature disappeared in Figures 3e and 3f. Such disappearance could be erroneously interpreted as a possible lithology termination between 3000 and 3025 m. Nevertheless, such disappearance is certainly a side effect of the Backus filtering process, as this northwestern heterogeneity appears again in the corresponding maps at $3050 \mathrm{~m}$ depth (see Figs. $4 \mathrm{~b}$ and $4 \mathrm{c}$ ) and at $3075 \mathrm{~m}$ depth (see Figs. 4e and 4f).

In order to interpret the influence of VTI anisotropy on the Young modulus, we now concentrate on the maps showing the residuals $\mathrm{E}_{\perp}-\mathrm{E}_{\|}$and the ratio $\mathrm{E}_{\perp} / \mathrm{E}_{\|}$(see Figs. 5 and 6). As depth increases, the ratio $\mathrm{E}_{\perp} / \mathrm{E}_{\|}$at 3000,3025 and $3075 \mathrm{~m}$ reveal zones in the center of the maps where the strength of VTI anisotropy is relatively higher. As the lithology columns of the reference wells in Figure 2 suggest, these zones of relatively higher strength of VTI anisotropy are certainly reflecting the dense set of thin layers forming the inner structure of the Namorado reservoir. However, the central region of the reservoir at $3025 \mathrm{~m}$ depth reveals the occurrence of a lithologic interval with very weak strength of VTI anisotropy. See the map showing the distribution of the differences $\mathrm{E}_{\perp}-\mathrm{E}_{\|}$in Figure 6a.

\section{CONCLUSIONS}

Using a data set containing information on bulk density, P- and S-wave sonic well log measurements, we mapped the spatial variation of dynamic Young moduli at specific depths through a turbidite-type oil reservoir formation. As shown in the corresponding maps, the isotropic approach for the Young modulus reveals a highly complex distribution of heterogeneities mainly due to a periodical sequence of sandstones and shales in the investigated sedimentary interval. Qualitatively, similar features corresponding to a high complex distribution of heterogeneities are observed in the depth maps for VTI Young moduli. These 

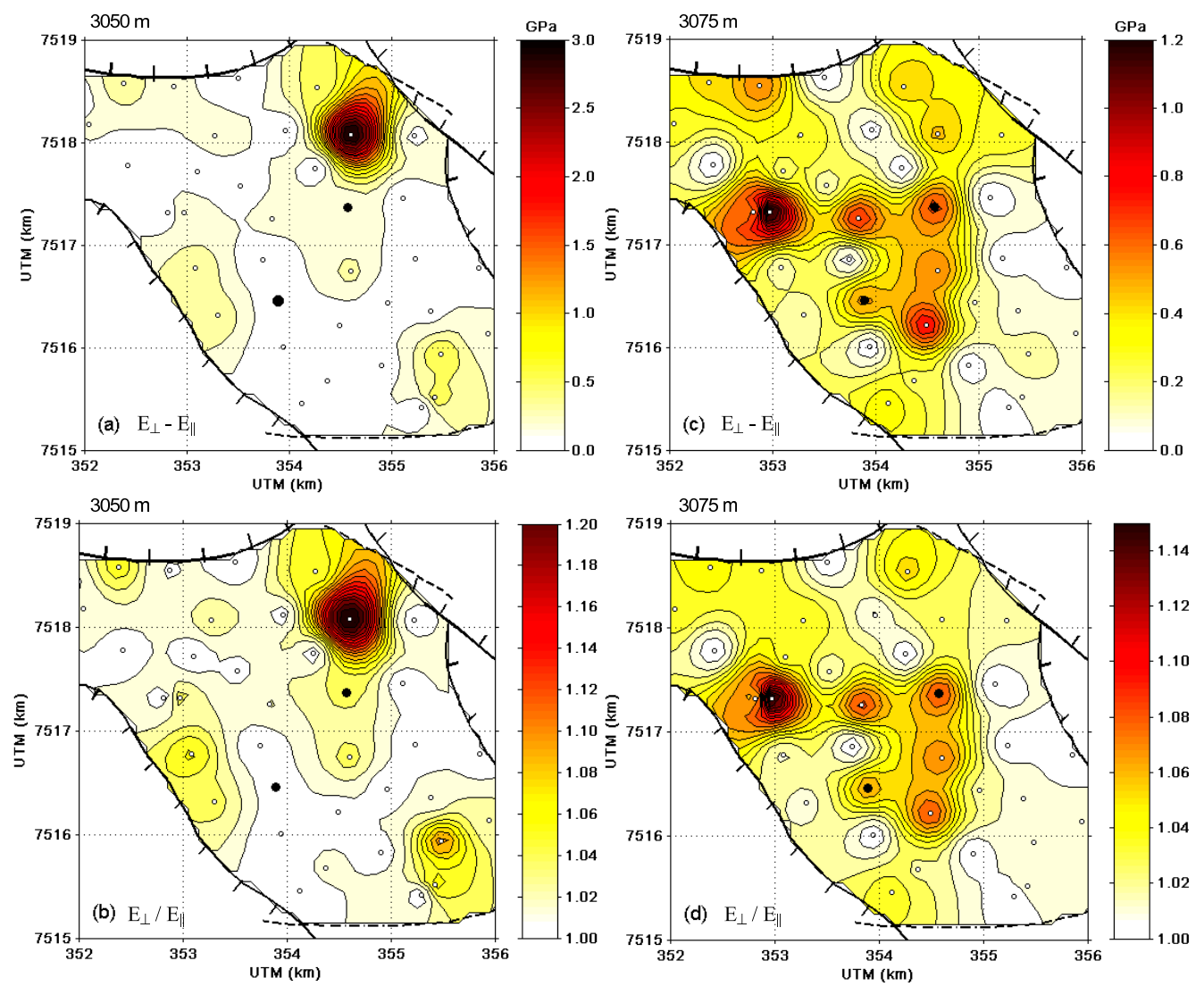

Figure 6 - Maps of the deviations of $\mathrm{E}_{\|}$from $\mathrm{E}_{\perp}$ (i.e., $\mathrm{E}_{\perp}-\mathrm{E}_{\|}$) and of the ratio $\mathrm{E}_{\perp} / \mathrm{E}_{\|}$. At $\underline{3050 \mathrm{~m}}$ depth $-(\mathrm{a}$ ) and (b); at $\underline{3075 \mathrm{~m}}$ depth $-(\mathrm{c})$ and (d). The maps of deviations $\mathrm{E}_{\perp}-\mathrm{E}_{\|}$are in (a) and (c). The ratio $\mathrm{E}_{\perp} / \mathrm{E}_{\|}$is plotted in (b) and (d). Filled circles locate the reference wells NA-01 and RJS-0019 (see Figs. 1 and 2).

features exhibited by the maps reveal the consistence of the methodology applied to the construction of the spatial variations of Young modulus. Particularly, the results point out the robustness of the inverse-distance square-weighted interpolator in Eq. (10), with assumption of $\mathrm{m}=2$ in Eq. (11). The statistical measures calculated in Table 1 give support to these observations. For a specific map type in the table, the calculation of statistical measures in three distinct scenarios yielded a noticeable stability in the interpolation of the Young modulus magnitudes.

As the inner structure of the reservoir is formed mainly by subhorizontal thin layers, the VTI anisotropy approximation for the correspondent sedimentary depth interval seems to be consistent with the theory of composite media. Use of Backus averaging technique provided a plausible degree of confidence on estimating effective VTI stiffnesses from the well log data set used. Comparing the isotropic maps for Young modulus, small magnitudes are observed in the maps of VTI Young moduli. This can be explained as a natural consequence of the Backus averaging technique, because it corresponds to a filtering operation designed with a frequency-dependent window size. The frequency content restrains the number of samples for filtering application. In this paper we assumed a frequency content of $40 \mathrm{~Hz}$, which allowed selecting a 55-sample window size for the application of Backus filtering. We presume that such window size was suitable for keeping the resolution in the studied thin-layered $200 \mathrm{~m}$ depth interval.

Finally, besides being a contribution to drill bit type selection in possible future drilling operations, the outcomes in this paper serve as additional information for geomechanical studies in the Namorado reservoir. For instance, Young modulus maps can be used in the analysis of wellbore stability in order to identify the occurrence of areas where the stress concentration exceeds the strength of the rock (i.e., breakout zones) at specific depths of the reservoir formation. Moreover, in situ stress analysis can benefit from assuming VTI anisotropy for the formation under analysis, as it is well-known that orientation and magnitude of in situ stresses change according to the assumption of isotropy or VTI anisotropy for sedimentary rocks. In this way, 
Table 1 - Uncertainty analysis using statistical measures of the interpolated Young modulus maps in Figures 3 and 4. Computation of minimum, maximum and mean values for maps of $\mathrm{E}, \mathrm{E}_{\|}$and $\mathrm{E}_{\perp}(\mathrm{GPa})$, as well as standard deviation $\sigma$ (GPa) and variance $\sigma^{2}\left(\mathrm{GPa}^{2}\right)$, assuming the following three scenarios: (a) the whole set of control points; (b) the overall points of the grid after interpolation; and (c) the interpolated values in the center of the map inside a circular region with radius of $1.5 \mathrm{~km}$. To analyze the data in the table, select a Young modulus depth map and consider a specific scenario for calculation of statistical measurements.

\begin{tabular}{|c|c|c|c|c|c|c|c|c|c|}
\hline $3000 \mathrm{~m}$ & \multicolumn{3}{|c|}{$\mathrm{E}$} & \multicolumn{3}{|c|}{$\mathrm{E}_{\|}$} & \multicolumn{3}{|c|}{$\mathrm{E}_{\perp}$} \\
\hline statistics & (a) & (b) & (c) & (a) & (b) & (c) & (a) & (b) & (c) \\
\hline $\mathrm{E}_{\min }$ & 12.84 & 12.96 & 12.96 & 4.55 & 4.61 & 4.61 & 4.78 & 4.84 & 4.84 \\
\hline $\mathrm{E}_{\max }$ & 60.35 & 60.27 & 57.32 & 19.14 & 19.11 & 18.27 & 19.50 & 19.47 & 18.60 \\
\hline $\mathrm{E}_{\text {mean }}$ & 22.00 & 22.56 & 20.88 & 8.87 & 9.02 & 8.56 & 9.05 & 9.18 & 8.72 \\
\hline$\sigma$ & 8.47 & 7.02 & 5.05 & 2.65 & 2.04 & 1.60 & 2.77 & 2.10 & 1.64 \\
\hline$\sigma^{2}$ & 71.71 & 49.33 & 25.50 & 7.05 & 4.16 & 2.57 & 7.67 & 4.41 & 2.69 \\
\hline $3025 \mathrm{~m}$ & \multicolumn{3}{|c|}{$\mathrm{E}$} & \multicolumn{3}{|c|}{$\mathrm{E}_{\|}$} & \multicolumn{3}{|c|}{$\mathrm{E}_{\perp}$} \\
\hline statistics & (a) & (b) & (c) & (a) & (b) & (c) & (a) & (b) & (c) \\
\hline $\mathrm{E}_{\min }$ & 11.70 & 11.94 & 11.94 & 5.67 & 5.69 & 6.06 & 5.82 & 5.83 & 6.16 \\
\hline $\mathrm{E}_{\max }$ & 38.01 & 38.05 & 36.65 & 16.60 & 16.57 & 15.83 & 16.70 & 16.68 & 15.94 \\
\hline $\mathrm{E}_{\text {mean }}$ & 21.38 & 21.66 & 21.61 & 8.64 & 8.77 & 8.59 & 8.91 & 9.03 & 8.89 \\
\hline$\sigma$ & 5.85 & 4.24 & 3.82 & 2.00 & 1.63 & 1.31 & 2.03 & 1.64 & 1.30 \\
\hline$\sigma^{2}$ & 34.26 & 18.01 & 14.57 & 4.00 & 2.66 & 1.72 & 4.13 & 2.69 & 1.69 \\
\hline $3050 \mathrm{~m}$ & \multicolumn{3}{|c|}{$\mathrm{E}$} & \multicolumn{3}{|c|}{$\mathrm{E}_{\|}$} & \multicolumn{3}{|c|}{$\overline{\mathrm{E}_{\perp}}$} \\
\hline statistics & (a) & (b) & (c) & (a) & (b) & (c) & (a) & (b) & (c) \\
\hline $\mathrm{E}_{\min }$ & 9.65 & 9.90 & 11.58 & 5.37 & 5.41 & 5.44 & 5.41 & 5.44 & 5.44 \\
\hline $\mathrm{E}_{\max }$ & 47.54 & 47.46 & 45.16 & 16.83 & 16.81 & 16.00 & 16.96 & 16.94 & 16.23 \\
\hline $\mathrm{E}_{\text {mean }}$ & 23.08 & 23.39 & 23.21 & 8.91 & 8.99 & 8.82 & 9.15 & 9.24 & 9.10 \\
\hline$\sigma$ & 7.81 & 5.77 & 5.03 & 2.23 & 1.69 & 1.34 & 2.41 & 1.83 & 1.58 \\
\hline$\sigma^{2}$ & 60.97 & 33.36 & 25.32 & 4.98 & 2.85 & 1.79 & 5.79 & 3.36 & 2.49 \\
\hline $3075 \mathrm{~m}$ & \multicolumn{3}{|c|}{$\mathrm{E}$} & \multicolumn{3}{|c|}{$\mathrm{E}_{\|}$} & \multicolumn{3}{|c|}{$\mathrm{E}_{\perp}$} \\
\hline statistics & (a) & (b) & $(c)$ & (a) & (b) & $(c)$ & (a) & (b) & (c) \\
\hline $\mathrm{E}_{\min }$ & 11.26 & 11.30 & 12.49 & 5.69 & 5.73 & 5.73 & 5.75 & 5.78 & 5.78 \\
\hline $\mathrm{E}_{\max }$ & 51.16 & 50.28 & 50.28 & 16.47 & 16.26 & 16.26 & 16.96 & 16.74 & 16.74 \\
\hline $\mathrm{E}_{\text {mean }}$ & 22.98 & 23.05 & 23.03 & 9.22 & 9.28 & 9.14 & 9.51 & 9.55 & 9.46 \\
\hline$\sigma$ & 8.00 & 5.47 & 4.92 & 2.37 & 1.71 & 1.52 & 2.43 & 1.75 & 1.53 \\
\hline$\sigma^{2}$ & 64.00 & 29.92 & 24.22 & 5.64 & 2.93 & 2.31 & 5.99 & 3.05 & 2.35 \\
\hline
\end{tabular}

construction of depth maps locating breakout zones and analysis of in situ stresses assuming VTI anisotropy would be a valuable additional information for well drilling planning, with highly positive impact on the economics of the field.

\section{ACKNOWLEDGMENTS}

This paper is product of the project "Caracterização de Anisotropia Sísmica usando Perfis Geofísicos de Poços de Petróleo e Gás", supported by CNPq/Brazil - the Brazilian Agency for the Development of Science \& Technology (proc. 471647/20063). Lidiane Garcia acknowledges support from CAPES/Brazil, for the development of a M.Sc. dissertation in the Post-Graduate Program on Geophysics at Observatório Nacional, Brazil. Jorge L. Martins acknowledges a research grant from CNPq/Brazil (proc. 302480/2011-0).

\section{REFERENCES}

AMADEI B. 1996. Importance of anisotropy when estimating and measuring in situ stresses in rock. Int. J. Rock Mech. Min. Sci. \& Geomech. Abstr., 33: 293-325.

AKI K \& RICHARDS PG. 1980. Quantitative Seismology - Theory and Methods. $2^{\text {nd }}$ ed., W.H. Freeman \& C0., 703 pp. 
AUGUSTO FOA. 2009. Mapas de amplitude sísmica para incidência normal no reservatório Namorado, bacia de Campos. M. Sc. Dissertation on Geophysics, ON/MCTI, 103 pp. (In Portuguese).

AUGUSTO FOA \& MARTINS JL. 2009. A well-log regression analysis for P-wave velocity prediction in the Namorado oil field, Campos basin. Brazilian Journal of Geophysics, 27(4): 595-608.

BACKUS GE. 1962. Long-wave elastic anisotropy produced by horizontal layering. Journal of Geophysical Research, 67: 4427-4440.

BAYUK 10, AMMERMAN M \& CHESNOKOV EM. 2008. Upscaling of elastic properties of anisotropic sedimentary rocks. Geophysical Journal International, 172: 842-860.

BELL JS. 2003. Practical methods for estimating in situstresses for borehole stability applications in sedimentary basins. Journal of Petroleum Science and Engineering, 38: 111-119.

DEWAN JT. 1983. Essentials of modern open-hole log interpretation. PennWell Books, 361 pp.

ELLISDV \& SINGER JM. 2007. Well logging for Earth scientists. $2^{\text {nd }}$ ed., Springer, $692 \mathrm{pp}$.

ERLING F, RUNE MH, PER H \& ARNE MR. 1991. Petroleum related rock mechanics. Elsevier, $338 \mathrm{pp}$.

HELBIG K. 1994. Foundations of Anisotropy for Exploration Seismics. Pergamon Press, 483 pp.

LASSO-LUCERO MA. 2010. Horizontal borehole stability in transversely isotropic media. M.Sc. Dissertation, University of Oklahoma, 125 pp.

LEE MW. 2006. A simple method of predicting S-wave velocity. Geophysics, 71: F161-F164.

LEVIN FK. 1984. Anisotropy due to bedding - A computer study. Geophys. Prosp., 32: 187-197.

LINER CL \& FEI TW. 2006. Layer-induced seismic anisotropy from fullwave sonic logs: theory, application and validation. Geophysics, 71 : D183-D190.

LONGUEMARE P, MAINGUY M, LEMONNIER P, ONAISI A, GÉRARD C \& KOUTSABELOULIS N. 2002. Geomechanics in reservoir simulation: overview of coupling methods and field case study. Oil \& Gas Science and Technology, Rev. IFP, 57: 471-483.
LOVE AEH. 1944. A treatise on the mathematical theory of elasticity. $4^{\text {th }}$ ed., Dover Publications, 643 pp.

NERY GG. 1990. Perfilagem geofísica em poço aberto. Apostila do Curso de Engenharia de Petróleo, Centro de Ensino da PETROBRAS, Salvador, $231 \mathrm{pp}$.

OLIVEIRA JS \& MARTINS JL. 2011. Spatial variation of angle-dependent impedance through a thin-layered oil reservoir. Brazilian Journal of Geophysics, 29: 811-829.

PENNINGTON WD. 2001. Reservoir geophysics. Geophysics, 66: 2530.

POSTMA GW. 1955. Wave propagation in a stratified medium. Geophysics, 20: 780-806.

SOARES JA. 1992. Um estudo da estabilidade mecânica de poços a partir de perfis geofísicos em formações pouco consolidadas. M.Sc. Dissertation on Geophysics, UFPA, 114 pp. (In Portuguese).

STOVAS A, LANDRØ M \& AVSETH P. 2006. AVO attribute inversion for finely layered reservoirs. Geophysics, 71: C25-C36.

TIGRE CA \& LUCCHESI CF. 1986. Estado atual do desenvolvimento da Bacia de Campos e perspectivas. In: Seminário de Geologia de Desenvolvimento e Reservatório, DEPEX-PETROBRAS, Rio de Janeiro, 1-12. (In Portuguese).

TIWARY DK, BAYUK IO, VIKHOREV AA \& CHESNOKOVEM. 2009. Comparison of seismic upscaling methods: from sonic to seismic. Geophysics, 74: WA3-WA14.

WEBER DD \& ENGLUND EJ. 1992. Evaluation and comparison of spatial interpolators. Mathematical Geology, 24: 381-391.

WEBER DD \& ENGLUNDEJ. 1994. Evaluation and comparison of spatial interpolators II. Mathematical Geology, 26: 589-603.

WRIGHT J. 1987. The effects of transverse isotropy on reflection amplitude versus offset. Geophysics, 52: 564-567.

ZOBACK MD. 2007. Reservoir geomechanics. Cambridge University Press, 464 pp. 


\section{NOTES ABOUT THE AUTHORS}

Lidiane de Souza Garcia holds a B.S. degree in Physics from Universidade Federal Rural do Rio de Janeiro, Brazil (2007). M.Sc. in the Post-Graduate Program on Geophysics at Observatório Nacional, Ministry of Science and Technology, Brazil (2011). Is a member of SBGf.

Jorge Leonardo Martins holds a B.S. degree in Civil Engineering from Universidade Veiga de Almeida (1986) and a Ph.D. in Applied Geophysics from Universidade Federal da Bahia, Brazil (1992). Was an associate researcher at Universidade Estadual do Norte Fluminense (1993-1998), visiting researcher at the Geophysical Institute of the Czech Academy of Science (April-June/1998), post-doctoral fellow at the SW3D Consortium Project (August/1998-January/2000), visiting researcher at Universidade Estadual de Campinas (2000), associate researcher at the Pontifícia Universidade Católica do Rio de Janeiro (2001), and visiting professor at Universidade do Estado do Rio de Janeiro (2002). Currently, senior researcher at Observatório Nacional, Ministry of Science and Technology, Brazil. Professional interests include theory and practice of seismic anisotropy, azimuthal AVO analysis, integration of seismics with well log petrophysics, multicomponent seismics, seismic inversion and seismic data processing. Is a member of EAGE, SEG and SBGf.

José Sampaio de Oliveira holds a B.S. degree in Physics from Universidade Federal Fluminense, Brazil (2007). Master dissertation (2010) in the Post-Graduate Program on Geophysics at Observatório Nacional (ON), Ministry of Science and Technology, Brazil. Is a doctoral student at ON, and a member of SBGf. 